\title{
Development of Extrapyramidal Symptoms in Hypertensive Patients Treated with Diazoxide
}

\author{
D. NEARY, H. THURSTON, J. E. F. POHL
}

\section{Summary}

Extrapyramidal symptoms developed a variable time after the start of treatment with oral diazoxide in $15 \%$ of a series of 100 severely hypertensive patients. Six illustrative cases are described. Treatment with diazoxide could be continued in four of these. The symptoms are usually controllable either by dosage adjustment or by the use of diazepam or procyclidine. There was no evidence of irreversibility of the extrapyramidal syndromes observed.

\section{Introduction}

Diazoxide, a non-diuretic benzothiadiazine vasodilator (Naylor et al., 1968; Schmitt et al., 1968) has recently been reintroduced into the long-term therapy of severe hypertension because of its effectiveness despite its many side effects (Finnerty, 1968; Pohl and Thurston, 1971; Pohl et al., 1972 a).

The characteristics and management of reduction in free water clearance by the kidneys (Pohl et al., 1972 b), renal sodium retention (Swales et al., 1972), and hyperglycaemia (Dollery et al., 1962; Wolff, 1964; Pohl and Thurston, 1971) have been well documented. Extrapyramidal side effects have not so far been attributed to diazoxide. During the acute and chronic management of 100 severely hypertensive patients with diazoxide (Pohl et al., $1972 \mathrm{c}$ ) the development of extrapyramidal symptoms was observed in $15 \%$. We report the following six illustrative cases, which represent the range of extrapyramidal syndromes encountered, and comment on the management of this new side effect of diazoxide.

\section{Case Reports}

Case 1.-A woman aged 21 presented with uncontrolled hypertension (blood pressure $200 / 140 \mathrm{~mm} \mathrm{Hg}$ ) secondary to chronic pyelonephritis. Her renal function was moderately impaired (creatinine clearance $21 \mathrm{ml} / \mathrm{min}$ ). Diazoxide therapy was begun and her blood pressure was easily controlled on an oral dose of $100 \mathrm{mg}$ four times a day. Two days later she complained of anxiety, irritability, and restlessness, together with trembling and clumsiness of the hands causing her to drop cups and cutlery. On examination she was restless and apprehensive and a coarse rhythmical tremor was seen in both outstretched hands. Brief irregular muscle contractions were seen in the thighs, the tendon reflexes were exaggerated, with bilateral patella and ankle clonus, but the plantar responses remained flexor. She was treated with diazepam $2 \mathrm{mg}$ three times a day by mouth and her symptoms and signs disappeared within 12 hours. Treatment with oral diazoxide $100 \mathrm{mg}$ three times a day was continued and her blood pressure remained controlled. Diazepam was discontinued within two weeks and her symptoms have not returned during $\mathbf{3 0}$ months of therapy.

\footnotetext{
Departments of Medicine and Neurology, Manchester Royal Infirmary, Manchester M13 9WL.

D. NEARY, M.B., M.R.C.P., Neurological Registrar

H. THURSTON, M.B., M.R.C.P., Lecturer in Medicine J. E. F. POHL, M.B., M.R.C.P., Lecturer in Therapeutics and Consultant
Physician
}

Case 2.-A pregnant woman aged 40 presented at 31 weeks gestation with severe pre-eclamptic toxaemia. A previous period of bed rest and a trial of therapy with methyldopa had been unsuccessful and her blood pressure had risen to $180 / 140 \mathrm{~mm} \mathrm{Hg}$ and was accompanied by severe headache and ankle oedema. Diazoxide was given by mouth in a dosage of $100 \mathrm{mg}$ three times a day. Her blood pressure was brought under control and she was free from headache. She remained well for two weeks while her serum diazoxide level slowly rose to $89 \mu \mathrm{g} / \mathrm{ml}$. On the 15 th day of treatment when her serum diazoxide level was $100 \mu \mathrm{g} / \mathrm{ml}$ she developed an overwhelming feeling of apprehension and anxiety, and her arms and legs began to shake uncontrollably. Estimated serum free diazoxide levels with a clear peak on the day on which symptoms occurred are shown in the graph. While clearly agitated, her facies was impassive, her speech lacked modulation, and her movements were slow. A continuous coarse rapid and rhythmical tremor was seen in the arms and legs, which was reduced by voluntary movement. She had cogwheel rigidity in all four limbs. The tendon reflexes were exaggerated and there was patella and ankle clonus but with flexor plantar responses. Since the patient had also developed a maculopapular itchy rash, attributed to diazoxide, the drug was discontinued. Her symptoms slowly subsided and disappeared over three days, while the serum diazoxide level fell to $63 \mu \mathrm{g} / \mathrm{ml}$. Subsequently the baby was delivered stillborn. The neurological features had not reappeared during the subsequent six months.

Case 3.-A man aged 66 with a spastic paraparesis due to spinal cord infarction secondary to a localized dissection of the abdominal aorta presented with severe hypertension (blood pressure 210/150 $\mathrm{mm} \mathrm{Hg}$ ), and severe azotaemia (creatinine clearance $<3 \mathrm{ml} / \mathrm{min}$ ). His hypertension was resistant to guanethidine and debrisoquine but his blood pressure was controlled with repeated intravenous injections of diazoxide varying in dosage from 50 to $300 \mathrm{mg}$. This treatment was complicated by postural hypotension accompanied by a transient loss of consciousness from which he recovered completely. He was subsequently stabilized on oral diazoxide $100 \mathrm{mg}$ four times a day. One week later when his blood pressure was under control he was noticed to have an impassive facies and monotonous speech. There was a glabellar tap, Parkinsonian tremor of the outstretched hands, and cogwheel rigidity in all four limbs. Diazoxide had to be continued and the patient's neurological signs persisted until his death one month later in renal failure.

Case 4.- A man aged 24 presented with advanced renal failure (creatinine clearance less than $2 \mathrm{ml} / \mathrm{min}$ ) complicated by severe hypertension $(220 / 150 \mathrm{~mm} \mathrm{Hg}$ ) which had remained unresponsive to conventional hypotensive agents. He had been taking high doses of methyldopa alone without any ill effects. His blood pressure was then brought under control with an oral dose of diazoxide $100 \mathrm{mg}$ twice a day together with methyldopa $250 \mathrm{mg}$ three times a day. Three weeks later, while his blood pressure was controlled and his renal function was improving he was noticed to be walking with a slow shuffling gait with flexion of the trunk and neck and loss of associated arm swinging. There was a poverty of voluntary and involuntary movement, an impassive facies, a glabellar tap, a mild Parkinsonian tremor, and rigidity in all four limbs. Tendon reflexes were exaggerated while the plantar responses remained flexor. These features persisted until two weeks later when he started on regular thrice-weekly haemodialysis. During haemodialysis therapy it was possible to tail off the diazoxide, and the neurological signs subsided.

Case 5.-A 44-year-old man presented with malignant hypertension (blood pressure $280 / 180 \mathrm{~mm} \mathrm{Hg}$ ) with mild impairment of renal function (creatinine clearance $34 \mathrm{ml} / \mathrm{min}$ ). His blood pressure was easily controlled with oral diazoxide $100 \mathrm{mg}$ four times a day and propranolol $20 \mathrm{mg}$ three times a day. He remained well until six weeks later when he was readmitted with a two-hour history of an overwhelming sensation of anxiety, tremulousness, and a sensation of movement in the abdomen, together with a choking sensation in the throat and a tightness of his jaw preventing him from opening his mouth. He was observed to be apprehensive and developed trismus on at least six occasions. No other involuntary movements were noted 
and there was no alteration in muscle tone or tendon reflexes. He was given an intramuscular injection of $10 \mathrm{mg}$ diazepam and his symptoms settled within 24 hours. Diazoxide and propranolol were continued in undiminished dosage, and over a period of three years there has been no recurrence of symptoms.

Case 6.-A woman aged 33 presented with uncontrolled hypertension (blood pressure $200 / 150 \mathrm{~mm} \mathrm{Hg}$ ) and renal failure (creatinine clearance $5.6 \mathrm{ml} / \mathrm{min}$ ). Her blood pressure was controlled with oral diazoxide $100 \mathrm{mg}$ three times a day. Her symptoms of severe headache and dyspnoea were abolished and her renal function began to improve. Two weeks later she became fearful and agitated with the rapid development of trismus and oculogyrus. On examination she was agitated and tremulous, her eyes were fixed in conjugate upward deviation and she had difficulty in opening her mouth which fluctuated from moment to moment. Power and tone in the limbs were normal, and while the tendon reflexes were exaggerated the plantar responses were flexor. Procyclidine $10 \mathrm{mg}$ intravenously was given and within 15 minutes she had returned to normal. Diazoxide was discontinued and she was maintained on an oral dose of procyclidine for a further three days without recurrence of her neurological symptoms. Three weeks later when her blood pressure had again begun to rise diazoxide was introduced at a lower dosage of $50 \mathrm{mg}$ three times a day and it was possible to maintain control of her blood pressure without the recurrence of any involuntary movement throughout a six-month period of observation.

\section{Discussion}

The existence of a category of hypertensives defined by general resistance to therapy and a very poor prognosis in the absence of adequate blood pressure control justified the reintroduction of diazoxide (Finnerty, 1968; Pohl and Thurston, 1971) which is effective in this situation but produces many side effects. The authors have gained wide experience in the long-term use of oral diazoxide, particularly in patients with impaired renal function (Thurston et al., 1973), and found that side effects can be successfully controlled in most patients by careful attention to clinical detail. Those physicians who are prepared to use diazoxide as a long-term hypotensive agent require an up to-date knowledge of all the side effects likely to be encountered and how they can be managed. In this context some importance attaches to the claim that diazoxide causes extrapyramidal syndromes and that this is not a rare side effect. Our evidence for this claim rests, firstly, on the appearance of the syndrome after the introduction of diazoxide when no other drugs were administered (except low dose methyldopa-case 4) which are known to cause this effect, and, secondly, on the relation to dosage and likelihood of accumulation of this drug and its disappearance when the diazoxide dosage could either be diminished or stopped. We would attach particular importance to case 2 where the calculated free diazoxide serum levels showed a sharp peak (see graph) which coincided with the onset of a severe Parkinsonian syndrome. The syndrome resolved with the fall of the free diazoxide level. Diazoxide accumulates in renal failure (J. E. F. Pohl, H. Thurston, and J. D. Swales, unpublished observations) and it is likely the diazoxide levels in cases 3 and 4 were high, though no measurements were made. Though some of the cases in our hypertensive series who showed extrapyramidal symptoms on diazoxide were also receiving methyldopa, which could provide an alternative explanation, there is a higher mean serum diazoxide level in the patients requiring treatment of their extrapyramidal symptoms (table).

The relevance of our observation to the clinical situation is clear. Milder cases, such as case 1 , presenting with restlessness may easily be misdiagnosed as functional in the absence of knowledge of the association, while more severe cases, especially the development of oculogyric crises (case 6), may lead to cessation of life-saving hypotensive therapy with diazoxide unless the treatable nature of the side effect is realized. The reversibility of the extrapyramidal syndromes attributed to diazoxide and the ease with which they can be suppressed with anti-Parkinsonian therapy must be stressed.

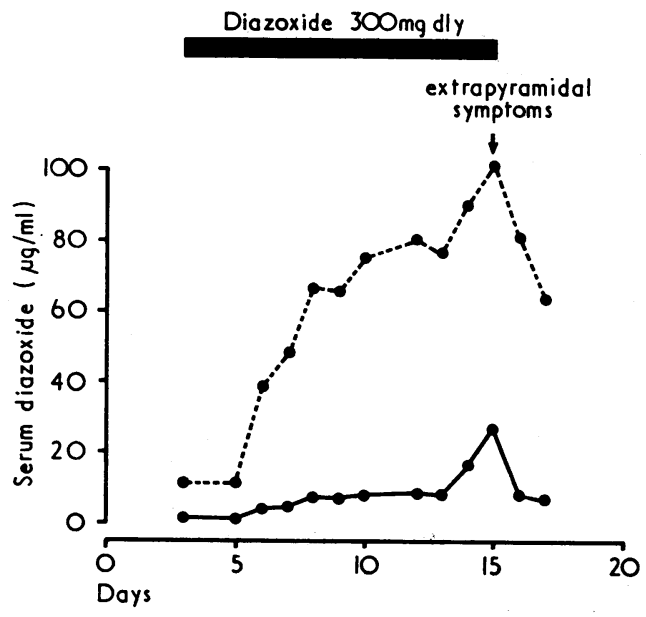

Division of 71 Patients with Adequate Serum Diazoxide Level Information According to Whether They Did or Did Not Require Anti-Parkinsonian Therapy

\begin{tabular}{|c|c|c|c|}
\hline & $\begin{array}{l}\text { No. of } \\
\text { Patients }\end{array}$ & $\begin{array}{c}\text { Serum Diazoxide } \\
(\mu \mathbf{m} / \mathbf{m l}) \\
(\text { Mean } \pm \text { S.D. }\end{array}$ & $\begin{array}{l}\text { Significance of } \\
\text { Difference }\end{array}$ \\
\hline $\begin{array}{l}\text { Patients requiring treatment } \\
\text { for extrapyramidal } \\
\text { symptoms } \\
\text { Patients not requiring treat- } \\
\text { ment for extrapyramidal } \\
\text { symptoms } \\
\text {.. }\end{array}$ & $\begin{array}{l}15 \\
56\end{array}$ & $\left.\begin{array}{l}98.8 \pm 24.42 \\
55.0 \pm 21.55\end{array}\right\}$ & $t=\underset{\mathrm{P}}{=}<0.31(70$ D.F. $)$ \\
\hline
\end{tabular}

Patients were bled one to two hours after the mid-day dose and had stable diazoxide levels on long-term therapy. The serum diazoxide levels were measured by extraction with ethyl acetate and spectrophotometric determination of absorbence at $280 \mathrm{mU}$ (Symchowicz et al., 1967).

We conclude that the evidence connecting oral long-term diazoxide therapy with the production of extrapyramidal symptoms is strong, but that this side effect is therapeutically manageable and should not be a common reason for discontinuing diazoxide therapy.

Requests for reprints should be addressed to: Dr. J. E. F. Pohl, University Department of Medicine, The Royal Infirmary, Manchester M13 9WL.

\section{References}

Dollery, C. T., Pentecost, B. L., and Saman, N. A. (1962). Lancet, 2, 735. Finnerty, F. (1968). Annals of the New York Academy of Sciences, 150, 461

Pohl, J. E. F., and Thurston, H. (1971). British Medical fournal, 4, 142

Pohl, J. E. F., Thurston, H., Davis, D., and Morgan, M. Y. (1972 a), British Medical fournal, 2, 568.

Pohl, J. E. F., Thurston, H., and Swales, J. D. (1972 b). Clinical Science, $42,145$.

Pohl, J. E. F., Thurston, H., and Swales, J. D. (1972 c). Transactions of Vth International Congress of Nephrology, Mexico, 1972.

Schmitt, H., Schmitt, H., and Laubie, M. (1968). Archives Internationales de Pharmacodynamie et dé Thérapie, 171, 339.

Sellers, E. M., and Koch-Weser, J. (1969). New England fournal of Medicine, 281, 1141 .

Swales, J. D., Thurston, H., and Pohl, J. E. F. (1972). Clinical Science, 43, 771 .

Symochowicz, S., et al. (1967). Fournal of Pharmaceutical Science, 56, 912. Thurston, H., Pohl, J. E. F., and Swales, J. D. (1973). Clinical Science, 45, July Suppl. 